\title{
Mongolia in Northeast Asia: Issues of Economic Development and Cooperation
}

\section{Khaisandai (Mongolia)}

eographically, Mongolia is a landlocked country in the heart of Asia
that is neighbored with two such great nations as Russia and China by
a historical destiny. The eastern part of our country entirely belongs to the Asia Pacific Division. As all of our geographical landscape has a location slanting to the direction of the Pacific Ocean, several of the freshest and the purest large rivers of the mainland has been sustaining the regions of Russia and China and their people for hundreds of years on their flows to the Pacific Ocean, as we all know. Moreover, other natural resources, wild lives, climate, and greeneries are closely connected to and interdependent with the regions of Russia and China in many ways. Therefore, Mongolia's environmental, ecological and economic diverse issues are inseparably related to East Asia, and even to whole Asia, as well as to Asia Pacific. These are only geographical and environmental aspects. From the perspective of geopolitics, Mongolia is a key strategic point connecting Northeast Asia to Central Asia and East Asia to Europe consequently through the shortest way. It means that Mongolia has a special location that functions as an essential junction for airways, railways, transportations and communications. In that sense, our country resembles a bridge linking the East with the West.

The sea outlet of our country can only be obtained through Russia and China. Eastern Asian countries have a source of capital and technique and technology that is of paramount importance for the further development of Mongolia that has been overcoming great challenges of transition to democracy and market economy. It is clear that Mongolia is beneficial for the countries in this region by its many advantages and factors such as natural resources, air, water, and various raw materials from agriculture. Thus, Mongolia has been intending to gain and strengthen her own status in East Asia, and to develop mutual and multilateral relations and cooperation by any means. This has become a very essential factor in ensuring the economic security and the development of our country.

Now let's take some examples as to what Mongolia's capacity is and what her 
wealth is. First of all, Mongolia has a territory of 1.5 million sq. km. There are 5 kinds (sheep, goat, cow, horse, camel) of traditional livestock with the number of over 40 million.

Moreover, our country is rich in its mining mineral resources. There are over 600 mining mineral deposits that have been pre-prospected and defined by their resources. From those deposits, the list of strategically important deposits was ratified by the Parliament in 2007. Primarily, 15 deposits have been included in the list. In the future, the number of such strategically important deposits is likely to increase more.

At present, the resources of specific 60 deposits have been calculated and are to be included in the list of strategically important deposits. From these deposits, namely, the deposit of Tavan Tolgoi has a resource of 6.7 billion tons of coal and of these 3.5 billion tons is coking coal, according researchers. Tavan Tolgoi has mineral resources that would last 30 years if 200 million tons is to be mined each year. Oyu Tolgoi Deposit has 6.4 billion tons of ore resources of which 45 million tons is copper and 2000 tons is gold respectively. It is calculated that the deposit can be exploited for 40 years, if 440 thousand tons of copper and 320 thousand ounces of gold is mined each year.

Besides these 2 deposits, there are Silver deposit of Asgat, zinc deposit in the Sukhbaatar aimag, petroleum deposit of Tamsag, uranium deposit in Dornod aimag are discovered the latest. And there is an uranium deposit in Khentii aimag, gold deposit of Olon Ovoot, and coal deposit of Nariin Sukhait, etc,.., all of whose amount of resources is not yet known.

As Russian geologists have calculated, there is around 2 million tons of uranium in our country out of which 40 thousand tones is confirmed. In the Gobi regions of Dornogobi, Sukhbaatar, Dundgobi, foreign experts' research to define resources is basically coming to an end upon uranium prospects.

The above mentioned figures are the data that was collected during the early strategic investments made to our country. Furthermore, it is observed that Mongolia's economy is to progress enormously to the development when strategically important coal, copper, gold, iron, ore, petroleum, uranium deposits like Tavan Tolgoi, Oyu Tolgoi, Tamsag, Mardai are to be exploited and refined. Above all, the economic security ensurance has been brought forward in the first place.

The concepts of relations with the Russian Federation and People's Republic of China are of paramount importance for the ensuring of the security of our country. Essentially, the main course of our foreign policy has been to cooperate with the Russian Federation and the People's Republic of China and will remain the same in the future.

Upon the consideration regarding the current level of involvement of the Russian Federation and the People's Republic of China in the economy of Mongolia, 
the following courses have been observed.

1. The joint factories of Mongolia and Russia that were invested in during the socialist period still remain the main economic sectors of Mongo lia. For instance, Erdenet, Ulaanbaatar Railroad and MongolRostSvetMet produce 20\% of GDP in combination. Although, from one side, the relation between Mongolia and Russia appears to be efficient, from other side, it indicates that the Russian Federation has not made a major investment and has not built a large size of factories in our country since 1990. The fact that the Russian Federation has come to be interested in the mining sector lately may become the beginning of a new course in the cooperation of not only our mutual countries, but also all our neighboring three countries.

2. There is a dominance of Chinese SMEs and individuals in expansion of foreign trade, whereby Chinese individuals access land and mining license using the names of Mongolians. 20 percent of Mongolia's entire trade turnover accounts for the Russian Federation now, and this num ber remained the same. Whereas, the involvement of China in Mongo lia's trade turnover has increased from 35 percent up to 60 percent in those years.

One specific feature of Mongolia's economic cooperation with the Russian Federation and the People's Republic of China since 2000 is that the majority of regional foreign trade turnover is of the subjects of Baikal region of the Russian Federation and of Inner Mongolia of the People's Republic of China.

The trade exchanges between people of those countries also belong to the cooperation of those regions. In the last few years mining sector became enormously important for Mongolian economy, increasing the tendency for state-owned and private large-scale multi-national corporations to enter Mongolian market and to run their operations has increased drastically.

Nowadays, it has become really crucial to adhere to the principle of mutual beneficence in the economic cooperation with our two neighbors. Since 1990 it was common to have rather unprofitable economic relations with the two countries. Just as the Mongolian trade with Russia brought deficit to Mongolia, so did the trade with China bring issues of competency of national (domestic) productions. In the economic relations with China, although the transactions between individuals appeared profitable to them in the predominance of individuals in the relations between China and Mongolia, it has clearly indicated that there is no competency in many Mongolian sectors such as cashmere processing, construction, and transportation.

Although cooperation between Mongolia and China in commerce and economy as well as in many other fields are being conducted beneficially in many ways, there are certain shortcomings which we have to note here. It is directly connected 
to some Mongolians being not committed enough to work and them withdrawing from what has already been negotiated and fixed. We are discussing these issues at all levels and are trying to reach a certain decision.

With regard to the aims to strengthen Mongolian economic security, it has to be studied thoroughly what issues need to be solved in the relations between Mongolia- Russia and Mongolia- China, and certain policies need to be processed. Moreover, in addition to the loans, aids, and investments of our two neighboring countries, those of Japan, the U.S.A, EU, Australia, India, Canada, South Korea and Turkey have increased, and consequently the roles and influences of those countries are expanding year by year.

Although it is a good result that the Mongolian economy has seen 6-10 percent increase in the last 5 years, this indication is mainly due to the mining sector. The resources of mining sector, first of all, are to exhaust fully one day, and, secondly, are directly dependent on the demands of external markets. Therefore, the structure of the Mongolian economy cannot remain dependent on mining sector only. From the experiences of other countries, it is clearly seen that as a result of high assets coming from mining sector, other industries fall back into recession leading foreign exchange rates to increase and national currency rates to drop. / Dutch disease/ The key negative consequence of this phenomenon is that it undermines development of national industry. Therefore, that country becomes fully dependent on the buyers of mining mineral resources. In the near 10 years, if Mongolian new economic structure doesn't get planned through the investment from the revenues of mining resources and consequently national industry doesn't get developed, the economic security may become bleak.

Experts have been calculating that the cost of mining crude materials is likely to remain the same in the next 10-15 years, and it is really necessary that the structural change of Mongolian economy be completed between these years. In order to do that, we should enhance the competency of our economy in the first place. That means we should assess the advantages and disadvantages of our economy and should develop new economic fields based on the advantages. However, today we are unable to see beyond the resources of mining sector. Unless we consider the matter comprehensively, assess domestic investments and reach a conclusion, we are so likely to expend the assets of mining sector on something that yields little profits.

Therefore, the most important thing that needs careful attention is that the assets of mining sector should be spent on creating new economic avenues and on supporting intellectual development. Before the natural mineral resources get diminished and exhausted in time, we should create some other new sectors, as aforementioned. New economic productive sectors based on high-tech are certain to advance our economy further 20-30 years later, if not now. In the future, Mongolia should become a production manufacturing country of high technol- 
ogy and high intellectual potential that has properly used its resources and that is ecological, rather than one having mining-predominant economy. The reason is that, firstly, our huge wealth is itself ecology and environment. Secondly, Mongolian has a small population. Countries with small populations are always unable to run labor intensive enterprises. Therefore, we should count that we will conduct knowledge intensive enterprises in the future.

It can be said that there are three main strategies that would bring about economic diversification.

The first of these is to develop brand new sectors. They have to be highly efficient sectors that would create high value addition. These would include, in the first place, biotechnology and nanotechnology. In those areas, several works have just started. We see that there is a possibility for Mongolia to get high technology develop intensively in the near future. We can conclude this to be a huge step crucial in creating diversification in our economy.

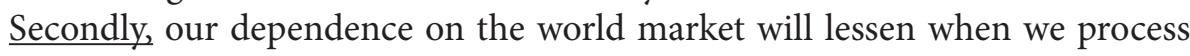
mineral ores and export final products.

Thirdly, in our economy there are several sectors that are developing and that have not yet reached world standards. Namely: food and agriculture, and tourism. It is possible to develop these sectors further immediately. I would like to emphasize "cultural industry" amongst them. By developing cultural industry that has been progressing intensively all over the world in the recent years, our economy will have an opportunity to compete in various sectors in the world market by its number of products. As a result, our economy will diversify to a great extent and will become less dependent on only mining sector, in our view. As a consequence of all these, the national security of our country will strengthen, and there rises an opportunity for Mongolia to expand its cooperation.

In conclusion, in order to increase the roles and importance of Mongolia in Northeast Asia and to better ensure the economic development and security, we should:

1. Make structural reform of Mongolian economy intensively and enhance competency drastically.

2. Balance the economic involvements of our great neighbors and run and implement a policy that would improve their efficiency.

3. Increase the economic involvement of such developed countries as Ja pan, EU, U.S.A, Canada, India, South Korea and Turkey; it is really im portant to develop mutual and multilateral cooperation with them, stimulate their interests in Mongolia, and introduce investments and the best technique and technology. These priorities must be taken into account together both in theory and in practice. 